\title{
Ultrasonographic Assessment of the Effect of Mode of Delivery on Postpartum Posterior Urethrovesical Angle : A Prospective Cohort Study
}

Original Article

\author{
Doaa M. Saleh
}

Department of Obstetrics and Gynecology, Faculty of Medicine, Al Azhar University for Girls, Cairo, Egypt

\begin{abstract}
Aim: This study aimed to investigate the impact of pregnancy and mode of delivery on postpartum posterior urethrovesical angle (PUVA) of continent women, as assessed by transperineal ultrasound (US).

Materials and Methods: The present study was a prospective study that included women with a singleton pregnancy and age-matched healthy volunteers as a control group. All patients underwent perineal US to assess the PUVA.

Results: One hundred pregnant women and 45 healthy controls were included. The baseline mean PUVA in pregnant women was $136.47 \pm 5.2^{\circ}$ at rest and $103.8 \pm 1.89^{\circ}$ at Valsalva maneuver; which were significantly higher than control group values $(p<0.001)$. Pregnant women had statistically significant higher PUVA at rest and Valsalva maneuver than a control group six weeks and six months after delivery $(p<0.001)$. Forty-one percent of the pregnant women underwent CS delivery, patients with VD had statistically significant higher PUVA at rest and stress six weeks after delivery than patients underwent CS delivery ( $p=0.014$ and 0.015 , respectively). Although a similar finding was observed at six months after delivery $(p=0.04)$. However, the difference in PUVA according to the mode of delivery at six months was clinically subtle

Conclusion: In conclusion, the VD has a clinically subtle impact on the PUVA six months after delivery when compared to CS delivery. Thus, elective CS delivery should not be recommended on the basis of fear of higher risks of UI after VD.
\end{abstract}

Key Words: Labour, posterior urethrovesical angle, pregnancy, transperienal US

Received: 30 July 2019, Accepted: 27 September 2019

Corresponding Author: Doaa M. Saleh, Department of Obstetrics and Gynecology, Faculty of Medicine, Al Azhar University for Girls, Cairo, Egypt, Tel.: : +20 1112987286, E-mail: dr.dodogyne@gmail.com

ISSN: 2090-7265, August 2021, Vol.11, No. 3

\section{INTRODUCTION}

Urinary incontinence (UI) is a prevalent condition that affect almost one in every four women aged 20 to 59 worldwide ${ }^{[1,2]}$. The disorder is a distressing condition that significantly deteriorate the quality of life and the perception of general health of the patients ${ }^{[3]}$. Stress UI is the most common presentation of incontinence, this disorder is significantly precipitated by wide range of risk factors such as obesity and diabetes ${ }^{[4]}$. Although UI can occur as a direct consequence of intrinsic sphincter weakness, it more commonly arises from pelvic floor dysfunction due to urethral hypermobility and weakness of the levator ani muscles ${ }^{[5,6]}$. The pelvic floor dysfunction may occur secondary to impairment in neural control such as diabetic neuropathy or neurologic disease; however, the dysfunction develops more commonly as a result of direct anatomical changes ${ }^{[7]}$.

Over the past few decades, anatomical injury after vaginal delivery (VD) and postmenopausal urogenital atrophy have been considered as one of the main risk factors for pelvic floor dysfunction ${ }^{[8]}$; the prevalence of postpartum incontinence in women underwent VD was reported to be as high as $35 \%{ }^{[9]}$. Therefore, the rate of elective cesarean section (CS) delivery has increased significantly in recent decades owing the concept of its potential protective effects on pelvic floor stability and sexual function ${ }^{[10,11]}$. Nevertheless, the impact of mood of delivery on pelvic hemodynamics is still debatable ${ }^{[12]}$. Recently, a growing body of evidence has shown that the pregnancy itself is one of the main contributors for impaired pelvic floor function; the hormonal changes during early pregnancy and the mechanical effects, especially in late pregnancy, were reported to significantly alter the structure and innervation of the pelvic floor muscle ${ }^{[13]}$.

Moreover, previous studies have reported a significant, temporary, loss of posterior urethrovesical angle after pregnancy and childbirth ${ }^{[14]}$.

However, the results of previous reports regarding the effect of pregnancy and the protective impact of CS delivery on the pelvic floor function were inconsistent ${ }^{[14,15]}$. 
Therefore, we conducted the present prospective cohort study to investigate the impact of pregnancy and mode of delivery on postpartum posterior urethrovesical angle of continent women, as assessed by transperienal ultrasound (US).

\section{PATIENTS AND METHODS}

We followed the Strengthening the Reporting of Observational studies in Epidemiology (STROBE) statement recommendations during the preparation of this report $^{[16]}$. The study's protocol gained the approval of the local ethics and research committee of Faculty of Medicine, Al-Azhar University, Cairo, Egypt. The present study runs in concordance with the Declaration of Helsinki principles and the guidelines of the International Committee of Medical Journal. A written informed consent was obtained from every eligible woman prior to study enrollment.

\section{Study Design, Setting and Participants:}

The present study was a prospective cohort study that was conducted at Obstetric and Gynecological outpatient clinics of Al-Azhar University Teaching Hospital through the period from March 2018 to August 2018. We included women aged less than 40 years old with singleton pregnancy. In addition, we included age-matched nulliparous volunteers as control group. Women with any chronic diseases as hypertension or diabetes; morbid obesity (defined as body mass index (BMI) $\geq 40 \mathrm{~kg} / \mathrm{m} 2$, or $\geq 35 \mathrm{~kg} / \mathrm{m} 2$ and experiencing obesity-related adverse health effects); conditions affecting pregnancy such as placenta previa, placenta accreta, severe intrauterine growth restriction, or pre-eclampsia; a difficult labour as macrosomic newborn, a breech delivery, or a shoulder dystocia delivery; connective tissue diseases; pelvic organ prolapse of any degree, stress urinary incontinence (SUI) pre-existing pregnancy; previous pelvic surgeries; or operative VD were excluded. We also excluded women who were smokers or had a history of drugs potentially affecting micturition.

\section{Sample size and Sampling Technique}

We used $G^{*}$ Power 3.0.1.0 software to calculate the required sample size. Based on previous report, the average posterior urethrovesical angle was reported to be $57^{\circ}$ six months postpartum, compared to an angel of $44.5^{\circ}$ among nulliparous women. With an alpha error of 5\% and power of $80 \%$, the required sample size was determined to be 51 women per group. A non-probability consecutive sampling technique was employed to recruit eligible women.

\section{Data collection and Study's Visits:}

The study consisted of three visits. The initial visit was conducted at 38-40 week of pregnancy and the following data was collected: demographic characteristics, mode of delivery, and transperineal ultrasound scan results. The transperineal ultrasound scans were repeated six weeks and six months after delivery. The primary outcome in the present study was the effect of pregnancy and mode of delivery on PFM function, as assessed by transperienal (US) assessment of the change in the posterior urethrovesical angle.

Trans-perineal US was performed with MINDRAY, SONOSCAPE ultrasound machines with a convex probe $3.5-\mathrm{MHz}$ using a translabial-perineal approach at midsagittal plane, and vaginal probe $6.5-\mathrm{MHz}$. After putting female in the lithotomy position,with half full bladder, we detect the uretherovesical junction (UVJ) at rest and during coughing and straining. The posterior urethro-vesical angle ' $\beta$-angle formed by the urethral axis and a line drawn tangent to the posterior edge of the bladder base near the bladder neck, was measured at rest and during straining. The proximal pubo-urethral distance was measured at rest and during straining.

\section{STATISTICAL ANALYSIS}

Data analysis and interpretation was conducted using SPSS (Statistical Package for the Social Science; SPSS Inc., Chicago, IL, USA) version 22 for Microsoft Windows. Quantitative data were described in terms of mean \pm standard deviation $( \pm \mathrm{SD})$, while qualitative data were expressed as frequencies (number of cases) and relative frequencies (percentages). Comparisons between quantitative variables were done using unpaired Student's t-test for parametric data or Mann-Whitney Rank Sum test for non-parametric data. Chi-square test was performed for categorical variables. A probability value ( $p$-value) less than 0.05 was considered statistically significant.

\section{RESULTS}

The present study included 100 pregnant women and 45 healthy controls. The mean age of the pregnant women was $25.3 \pm 4.7$ years compared to $25.9 \pm 4.7$ years in the control group $(p=0.532)$. The mean weight was significantly higher in pregnant women $(75.45 \pm 9.2$ versus $70.22 \pm 7.3 \mathrm{~kg}$ in control group; $p<0.001)$. The baseline mean posterior urethrovesical angle in pregnant women was $136.47 \pm 5.2^{\circ}$ at rest and $103.8 \pm 1.89^{\circ}$ at Valsalva maneuver; which were significantly higher than control group values $(p<0.001)$. Table 1 showed the demographic characteristics of the included women.

Forty-one percent of the pregnant women underwent CS delivery. At week 6 after delivery, the pregnant women had statistically significant higher posterior urethrovesical angle at rest than control group (124.26 $\pm 5.3^{\circ}$ versus $105.88 \pm 1.89^{\circ}$, respectively; $\left.p<0.001\right)$. Similarly, pregnant women had statistically significant higher posterior urethrovesical angle at Valsalva maneuver. Six months after delivery, pregnant women had statistically significant higher posterior urethrovesical angle at rest 
than control group $\left(112.83 \pm 4.66^{\circ}\right.$ versus $103.71 \pm 1.77^{\circ}$, respectively; $p<0.001)$. A similar finding was observed for posterior urethrovesical angle at Valsalva maneuver (Table 2). Regarding the impact of mode of delivery on posterior urethrovesical angle, patients with VD had statistically significant higher posterior urethrovesical angle at rest and stress six weeks after delivery than patients underwent CS delivery ( $p=0.014$ and 0.015 , respectively). Although a similar finding was observed at six months after delivery ( $p=0.04$ ), However, the difference in PUVA according to mode of delivery at six months was clinically subtle (Figure 1).

Table 1: Baseline characteristics of the included subjects

\begin{tabular}{|c|c|c|c|}
\hline Variables & Pregnant Women $(\mathrm{N}=100)$ & Control $(\mathrm{N}=50)$ & P-value \\
\hline Age (years), mean $\pm \mathrm{SD}$ & $25.3 \pm 4.7$ & $25.9 \pm 4.7$ & 0.532 \\
\hline Weight $(\mathrm{Kg})$, mean \pm SD & $75.45 \pm 9.2$ & $70.22 \pm 7.3$ & $<0.001$ \\
\hline PUVA at rest, mean \pm SD & $136.47 \pm 5.2$ & $103.8 \pm 1.89$ & $<0.001$ \\
\hline PUVA at Valsalva, mean \pm SD & $145.35 \pm 5.89$ & $112.11 \pm 2.08$ & $<0.001$ \\
\hline \multicolumn{4}{|l|}{ Mode of delivery, No (\%) } \\
\hline $\begin{array}{l}\text { VD } \\
\text { CS }\end{array}$ & $\begin{array}{l}59(59 \%) \\
41(41 \%)\end{array}$ & ---- & --- \\
\hline
\end{tabular}

Table 2: Postpartum PUVA of the included subjects

\begin{tabular}{|c|c|c|c|}
\hline Variables & Pregnant Women $(\mathrm{N}=100)$ & Control $(\mathrm{N}=50)$ & $P$-value \\
\hline PUVA at rest (6 weeks), mean \pm SD & $124.26 \pm 5.3$ & $105.88 \pm 1.89$ & $<0.001$ \\
\hline $\begin{array}{l}\text { PUVA at Valsalva ( } 6 \text { weeks), } \\
\text { mean } \pm \text { SD }\end{array}$ & $130.97 \pm 5.6$ & $112.31 \pm 1.89$ & $<0.001$ \\
\hline PUVA at rest ( 6 months), mean \pm SD & $112.83 \pm 4.66$ & $103.71 \pm 1.77$ & $<0.001$ \\
\hline $\begin{array}{l}\text { PUVA at Valsalva ( } 6 \text { months), } \\
\text { mean } \pm \text { SD }\end{array}$ & $116.81 \pm 4.6$ & $112.31 \pm 1.89$ & $<0.001$ \\
\hline
\end{tabular}

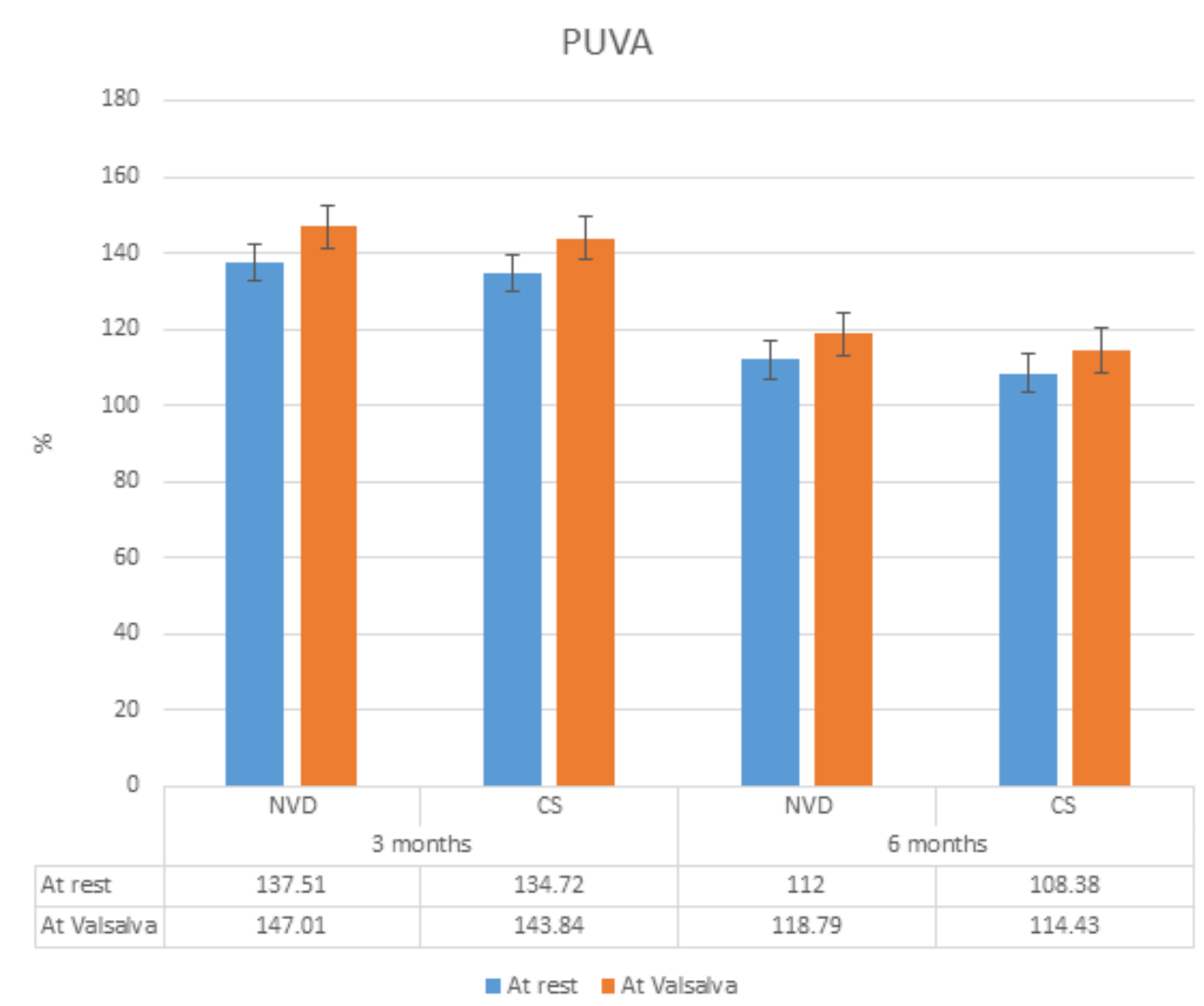

Fig. 1: The difference in PUVA between women with NVD and CS at 3 and 6 months after delivery 


\section{DISCUSSION}

Pregnancy and delivery are one of the well-established risk factors of postpartum UI and genital organs prolapse. However, the impact of mode of delivery on pelvic floor muscle function among women who did not develop UI is still unclear. In the present study, continent women showed statistically significant higher values of posterior urethrovesical angle at rest and valsalva maneuver from six week after delivery till the third month postpartum. However, the values of posterior urethrovesical angle in pregnant women decreased to near the normal range of the angle six months after delivery. Although, women who underwent VD had higher values of postpartum posterior urethrovesical angle to women underwent CS after six months of delivery, the postpartum posterior urethrovesical angle was within normal accepted range in both groups.

Posterior urethrovesical angle is the angle between the floor of the bladder and upper part of urethra which is situated normally at $90-100^{\circ}$; previous reports showed that the increase in the posterior urethrovesical angle is significantly correlated with development of UI and prolapse $^{[17]}$. On the other hand, transperineal US has gained much popularity over the past three decades as a valid and reliable assessment tool of pelvic floor anatomy and physiology ${ }^{[18]}$. According to Alper and colleagues ${ }^{[19]}$, significant changes in the posterior urethrovesical angle widening at rest and at Valsalva maneuver which predispose to UI- can be demonstrated and proved by transperineal US. In the present study, we utilized transperineal US to assess the change in the posterior urethrovesical angle till the sixth month after delivery; we found that pregnancy and labour had a transient effects on posterior urethrovesical angle among continent women that lasted from six weeks before delivery to the third month postpartum. However, the values of posterior urethrovesical angle return to their normal accepted range six months after delivery. In agreement with our findings, Wijma and colleagues ${ }^{[20]}$ reported that pregnant women had significantly more widening of the angle of the urethrovesical junction six months after VD, compared to nulliparous women. Another prospective study that the urethrovesical angle and the urethral mobility increased significantly 3 months after delivery ${ }^{[21]}$.

According to recent global figures, there is a continuous, dramatic, increase in the rate of CS delivery worldwide, the rate of CS delivery increased from $6.7 \%$ in 1990 to $19.1 \%$ in 2014 , while the rate was much higher in Egypt $(51.8 \%)^{[22]}$. It was reported that one of the reasons for this increased trends of CS delivery is the fear of genital modifications after VD, with their subsequent effects on postpartum pelvic floor muscle function ${ }^{[23-25]}$. In the present study, patients with VD had statistically significant higher posterior urethrovesical angle three months after delivery than patients with CS. Although, women who underwent VD had higher values of postpartum posterior urethrovesical angle to women underwent CS after six months of delivery; however, the difference in PUVA according to mode of delivery at six months was clinically subtle. These findings can reflect that the postpartum change in pelvic floor muscle function can be related to pregnancy itself, rather than the mode of delivery. In concordance with our findings,

We acknowledge that the present study has a number of limitations. The study was conducted in one center only which may affect the generalizability of our findings. Another limitation is the disproportional sample size between pregnant women and age-matched healthy controls.

\section{CONCLUSION}

In conclusion, the present study showed that pregnancy and delivery negatively affect the posterior urethrovesical angle, as assessed by transperienal US. Pregnant women had sustained higher values of posterior urethrovesical angle over a period of six months after delivery, compared to healthy nulliparous women. On the other hand, the VD did not have a notable impact on the posterior urethrovesical angle six months after delivery when compared to CS delivery. Thus, elective CS delivery should not be recommended on the basis of fear of higher risks of UI after VD. Further long-term studies are still needed to confirm our findings and to study the impact of the change in the postpartum posterior urethrovesical angle on the PFM dysfunction-related disorders.

\section{CONFLICT OF INTEREST}

There are no conflicts of interests.

\section{REFERENCES}

1. Hendrix SL, Clark A, Nygaard I, Aragaki A, Barnabei V, McTiernan A. Pelvic organ prolapse in the Women's Health Initiative: Gravity and gravidity. Am. J. Obstet. Gynecol., vol. 186, 2002, p. 1160-6. doi:10.1067/mob.2002.123819.

2. Hannestad YS, Rortveit G, Sandvik H, Hunskaar S. A community-based epidemiological survey of female urinary incontinence: The Norwegian EPINCONT Study. J Clin Epidemiol 2000;53:1150-7. doi:10.1016/S0895-4356(00)00232-8.

3. Frota IPR, Rocha ABO, Neto JAV, Vasconcelos CTM, De Magalhaes TF, Karbage SAL, et al. Pelvic floor muscle function and quality of life in 
postmenopausal women with and without pelvic floor dysfunction. Acta Obstet Gynecol Scand 2018;97:552-9. doi:10.1111/aogs.13305.

4. Johnston S. Stress urinary incontinence treatment: Focus should be on identifying best candidates for surgical success in the first place. Can Urol Assoc J 2017;11:281-2. doi:10.5489/cuaj.4801.

5. Sangsawang B, Sangsawang N. Stress urinary incontinence in pregnant women: A review of prevalence, pathophysiology, and treatment. Int Urogynecol J 2013. doi:10.1007/s00192-013-2061-7.

6. Delancey JOL. The pathophysiology of stress urinary incontinence in women and its implications for surgical treatment. World $\mathrm{J}$ Urol 1997. doi:10.1007/BF02202011.

7. Jundt K, Peschers $U$, Kentenich $H$. The Investigation and Treatment of Female Pelvic Floor Dysfunction. Dtsch Aerzteblatt Online 2015. doi:10.3238/arztebl.2015.0564.

8. Raz R, Stamm W. A controlled trial of intravaginal oestriol in postmenopausal women with recurrent urinary tract infection. J Obstet Gynaecol (Lahore) 1994;14. doi:10.3109/01443619409015471.

9. Thom DH, Rortveit G. Prevalence of postpartum urinary incontinence: A systematic review. Acta Obstet Gynecol Scand 2010. doi:10.3109/00016349.2010.526188.

10. Ghetti C, Chan BKS, Guise JM. Physicians' responses to patient-requested cesarean delivery. Birth 2004;31:280-4. doi:10.1111/j.0730-7659.2004.00320.x.

11. Al-Mufti R, McCarthy A, Fisk NM. Survey of obstetricians' personal preference and discretionary practice. Eur $\mathrm{J}$ Obstet Gynecol Reprod Biol 1997;73:1-4. doi:10.1016/S0301-2115(96)02692-9.

12. Press JZ, Klein MC, Kaczorowski J, Liston RM, von Dadelszen P. Does Cesarean Section Reduce Postpartum Urinary Incontinence? A Systematic Review. Birth 2007;34:228-37. doi:10.1111/ j.1523-536X.2007.00175.x.

13. Lose G. Anatomical and functional changes in the lower urinary tract during pregnancy. Am J
Obs Gynecol 2001;108:726-32. doi:10.1067/ mob.2001.114501.

14. Elenskaia K, Thakar R, Sultan AH, Scheer I, Beggs A. The effect of pregnancy and childbirth on pelvic floor muscle function. Int. Urogynecol. J., vol. 22, 2011, p. 1421-7. doi:10.1007/s00192011-1501-5.

15. Bø K, Hilde G, Jensen JS, Siafarikas F, Engh ME. Too tight to give birth? Assessment of pelvic floor muscle function in 277 nulliparous pregnant women. Int. Urogynecol. J. Pelvic Floor Dysfunct., vol. 24, 2013, p. 2065-70. doi:10.1007/ s00192-013-2133-8.

16. Elm E Von, Altman DG, Egger M, Pocock SJ, Gøtzsche PC, Vandenbroucke JP, et al. The Strengthening the Reporting of Observational Studies in Epidemiology ( STROBE ) Statement : Guidelines for reporting observational studies *. Int J Surg 2014;12:1495-9. doi:10.1016/j. ijsu.2014.07.013.

17. Unlubilgin E, Karasu Y, Ozdogan S, Karadag B, Dolen I. The size of posterior urethrovesical angle change affects the success of sling operations. Clin Exp Obstet Gynecol 2017. doi:10.12891/ $\operatorname{ceog} 3626.2017$.

18. Torella M, De Franciscis P, Russo C, Gallo P, Grimaldi A, Ambrosio D, et al. Stress urinary incontinence: Usefulness of perineal ultrasound. Radiol Medica 2014. doi:10.1007/s11547-013-0317-4.

19. Alper T, Cetinkaya M, Okutgen S, Kökçü A, Malatyalioğlu E. Evaluation of urethrovesical angle by ultrasound in women with and without urinary stress incontinence. Int Urogynecol $\mathrm{J}$ Pelvic Floor Dysfunct 2001;12:308-11.

20. Wijma J, Weis Potters AE, De Wolf BTHM, Tinga DJ, Aarnoudse JG. Anatomical and functional changes in the lower urinary tract following spontaneous vaginal delivery. BJOG An Int J Obstet Gynaecol 2003. doi:10.1016/S1470-0328(03)02296-1.

21. Costantini S, Esposito F, Nadalini C, Lijoi D, Morano S, Lantieri P, et al. Ultrasound imaging of the female perineum: The effect of vaginal delivery on pelvic floor dynamics. Ultrasound Obstet Gynecol 2006. doi:10.1002/uog.2663. 
22. Betrán AP, Ye J, Moller A-B, Zhang J, Gülmezoglu AM, Torloni MR. The Increasing Trend in Caesarean Section Rates: Global, Regional and National Estimates: 1990-2014. PLoS One 2016;11:e0148343. doi:10.1371/journal. pone.0148343.

23. Hellerstein S, Feldman S, Duan T. China's 50\% caesarean delivery rate: Is it too high? BJOG An Int J Obstet Gynaecol 2015;122:160-4. doi:10.1111/1471-0528.12971.
24. Torloni MR, Daher S, Betrán AP, Widmer M, Montilla P, Souza JP, et al. Portrayal of caesarean section in Brazilian women's magazines: 20 year review. BMJ 2011;342:324. doi:10.1136/bmj.d276.

25. Van Brummen HJ, Bruinse HW, Van De Pol G, Heintz APM, Van Der Vaart CH. Which factors determine the sexual function 1 yearafterchildbirth? BJOG An Int J Obstet Gynaecol 2006;113:914-8. doi:10.1111/j.1471-0528.2006.01017.x. 